\title{
Effect of Salinity Stress on Slow- and Fast- Growing Festuca Grass Species
}

\author{
W. S. Soliman* and S. Sugiyama** \\ *Department Horticulture, Faculty of Agricultural and Natural \\ Resources, Aswan University Aswan, Egypt and ${ }^{* *}$ Lab of Plant \\ Ecology Faculty of Agricultural and Life Science, Hirosaki \\ University, Hirosaki, Japan.
}

\begin{abstract}
MPROVING tolerance to salinity stress is a major challenge in many regions worldwide. In this study, the effect of salinity stress on slow- and fast-growing Festuca species was examined. Plants were exposed to $0,50,100$ or $200 \mathrm{mM}$ of $\mathrm{NaCl}$ for two weeks in a greenhouse using a hydroponic culture system. Shoot dry mass, water status, membrane stability were monitored as well as contents of proline, sodium, potassium, calcium, magnesium, nitrogen and phosphorus. Salinity stress had negative effects on shoot dry mass, water status, and membrane stability. Although fast-growing species had higher shoot dry mass, the slope of decreases were much higher in the fast-growing species. Slow-growing species showed greater accumulation of $\mathrm{Na}^{+}$, greater increases in ion leakage and $\mathrm{Mg}$ content and greater decreases in proline content. The results suggested that the interspecific differences among species in resistance to salinity stress associated mainly with tolerance ability to salinity stress rather than avoidance ability. The difference is due mainly to growth habits which is associated mainly with relative growth rate and leaf properties. Also, there was interference of $\mathrm{Mg}$, but not $\mathrm{Ca}$, on $\mathrm{Na}^{+}$uptake by plant shoot, in addition to the important role of proline content in tolerance mechanism.
\end{abstract}

Keywords: Festuca grass, Interspecific difference, $\mathrm{Na}^{+}$, Proline, Salinity stress

Salinity stress is one of the major environmental stress limiting growth and productivity of plants. One-third of the irrigated land suffers from salinity, especially in the arid and semiarid regions (Taiz and Zeiger, 2002 \& FAO, 2011). The main sources of the accumulated salts in arable soils are seawater and the irrigation water that contains sodium chloride $(\mathrm{NaCl})$ (Flowers \& Yeo, 1995 and Tester \& Davenport, 2003).

Plants differ greatly in their tolerances to salinity stress either among species or populations within the same species (Munns \& Tester, 2008, Witzel et al., 
2009 and Amjad et al., 2014). Plants are damaged by salinity stress in several ways including early occurring osmotic stress, ionic stress, oxidative stress, alteration in metabolic processes, nutritional disorders, membrane disorganization, reduction of cell division and expansion and/or genotoxicity (Munns, 2002, Munns \& Tester, 2008 and Carillo et al., 2011). Ionic damage occurs when salts accumulate in plant tissues at toxic level. Accumulation of $\mathrm{Na}^{+}$ ion in plant tissues at excessive levels is one of the major factors causing salinity damage (Flowers \& Hajibagheri, 2001 and Mitsuya et al., 2003). Increasing the concentration of salt such as $\mathrm{NaCl}$ in the soil reduces the ability of plants to uptake the water. The accumulation of ionic $\mathrm{Na}^{+}$in plant tissue impairs the metabolic processes and decreases the photosynthetic efficiency which in turn negatively effect on the plant growth (Flowers \& Yeo, 1995 and Mäser et al., 2002). Although many studies have explored plants response and resistance to salinity stress, many challenges still lie ahead for understanding the key traits that confer such tolerance (Vinocur \& Altman, 2005, Bartels \& Sunkar, 2005 and Deinlein et al., 2014).

In this study, comparison experiment was conducted among four Festuca grass species differed in their growth habit, two slow-growing and two fastgrowing species, under different salinity levels using hydroponic system to clarify how species differs in their responses to salinity stress. The objectives of this study were (1) to clarify the interspecific differences in salinity tolerance among species, (2) to illustrate if species growth properties influence tolerance trait, and (3) to ascertain whether response to salinity stress interference with ions uptake and proline content.

\section{Materials and Methods}

\section{Plant materials and growth conditions}

Four species belonging to Festuca genus were used in this study, fastgrowing species (Festuca arundinacea Schreb., F. pratensis Huds.), and slowgrowing species ( $F$. ovina L., $F$. rubra L). This study was conducted in a greenhouse using a hydroponic culture system during June-July, 2014. Plants were grown in plastic nursery trays placed on 25-L containers, with half-strength modified Hogland and Arnon No. 2 nutrient solution (Sugiyama and Nikara, 2004). The full-strength modified Hogland and Arnon No. 2 nutrient solution contains macronutrients in $\mathrm{mM}, \mathrm{N}$ 15.0, $\mathrm{P}$ 1.0, K 6.0, Ca 4.0 and $\mathrm{Mg} 2.0$, along with micronutrients in $\mu \mathrm{M}, \mathrm{B} 3.0, \mathrm{Mn} \mathrm{0.5,} \mathrm{Cu} \mathrm{0.2,} \mathrm{Zn} \mathrm{0.4,} \mathrm{Mn} \mathrm{0.05,} \mathrm{and} \mathrm{Fe-}$ EDTA 20.0. After 40 days, the plants were exposed to salinity stress using $\mathrm{NaCl}$ with concentrations of $0,50,100$, and $200 \mathrm{mM}$ for two weeks. The $\mathrm{pH}$ was adjusted daily at 5.5 using $1 \mathrm{~N} \mathrm{H}_{2} \mathrm{SO}_{4}$ and/or $\mathrm{NaOH}$. The nutrient solution was renewed every two weeks. Aeration was supplied at a rate of $2 \mathrm{~L} / \mathrm{min}$ using a mini pump throughout the experiment. The experiment was set up as a randomized block layout.

Egypt. J. Hort. Vol. 43, No.1 (2016) 


\section{Physiological measurement and chemical analysis}

After two weeks of salinity treatments, plants were harvested and divided into two sets (each set contain four replicates). A set of plants was used to measure cell membrane stability and leaf water status. Cell membrane stability was measured by ion leakage (IL) from leaf tissues using the methods described by Jiang and Huang (2002). Leaf water status was measured by relative water content (RWC) according to Loutfy et al. (2012) as,

$$
R W C(\%)=\frac{F W-D W}{T W-D W} \times 100
$$

where $F W$ is the fresh weight, $D W$ is the dried weight and $T W$ is the turgid weight of tissue after being soaked in water for $12 \mathrm{~h}$ at room temperature.

Another set of plants were cut below the stem base and were separated into shoots and roots. Shoots were dried at $70^{\circ} \mathrm{C}$ for $48 \mathrm{~h}$ in a forced-air oven, then the dry weights were recorded. Free proline was determined according to Bates et al. (1973). Briefly, dried shoots after grinding $(0.2 \mathrm{~g})$ was homogenized in $10 \mathrm{ml}$ of $3 \%$ aqueous sulfosalicylic acid for $10 \mathrm{~min}$ followed by filtration. Two milliliters of the filtrate were mixed with $2 \mathrm{ml}$ of glacial acetic acid and $2 \mathrm{ml}$ of acid ninhydrin, and the mixed solution was heated in water path for $1 \mathrm{~h}$. The developed color was extracted in $4 \mathrm{ml}$ toluene and measured colourimetrically at $520 \mathrm{~nm}$ against toluene. A standard curve with proline was used for calculate the final concentrations. For chemical analysis, dried plant shoots $(0.2 \mathrm{~g})$ were wetdegisted with concentrated $\mathrm{H}_{2} \mathrm{SO}_{4}: \mathrm{H}_{2} \mathrm{O}_{2}(1: 1, \mathrm{v} / \mathrm{v})$ using a heating digester (DK, Velp Scientific srl, Italy). The extracts were used for chemical analysis. Nitrogen content was measured using TOC analyzer (TOC-L, Shimadzu Corporation, Japan). Phosphorous (P) content was measured colourimetrically using UV-VIS Spectrophotometer. Sodium $\left(\mathrm{Na}^{+}\right)$, potassium $\left(\mathrm{K}^{+}\right)$, calcium $\left(\mathrm{Ca}^{+2}\right)$ and magnesium $\left(\mathrm{Mg}^{+2}\right)$ were analyzed using Polarized atomic absorption spectrophotometer (Z-2000, Hitachi Ltd., Tokyo, Japan).

\section{Statistical analysis}

The statistical analysis was carried out using JMP (versions 4.0, SAS Institute Inc., USA). The statistical difference among salinity treatments was tested by analysis of variance (ANOVA) for each species. The experiment was set up in a randomized block layout incorporating four replications for each set.

\section{Results}

Under control conditions, the four species differed greatly in shoot dry mass and contents of proline, nitrogen and phosphorus. The other traits showed no significant differences under control conditions. One-way ANOVA revealed significant changes in shoot dry mass, water status as expressed by relative water 
content (RWC), membrane stability as expressed by ion leakage (IL), and chemical components under salinity stress in different Festuca grass species (Table 1). Fig. 1 showed significant decreases in shoot dry mass, RWC, and nitrogen content, while sodium $\left(\mathrm{Na}^{+}\right)$and phosphorus $(\mathrm{P})$ contents increased significantly in the four species with increasing $\mathrm{NaCl}$ concentration in culture solution. The slow-growing species, F. ovina and F. rubra, showed significant decreases in proline content and significant increases in IL and $\mathrm{Mg}$ content under salinity stress. On the other hand, fast-growing species, $F$. arundinacea and $F$. pratensis, showed no significant changes in $\mathrm{IL}, \mathrm{Mg}$, and proline content under stress. Also, no significant changes were shown in potassium $(\mathrm{K})$ and calcium (Ca) contents in both fast-growing and slow-growing species.

The grass $F$. pratensis had the highest shoot dry mass followed by $F$. arundinacea, F. rubra, and $F$. ovina at all levels of salinity stress, however the slope of decreases was much higher in $F$. pratensis compared to other species (Fig. 1). Proline content was significantly higher in the slow-growing species compared to fast-growing species under control conditions. In contrast, proline content was significantly higher in the fast-growing species under salinity stress. The decreases in RWC were much higher in $F$. arundinacea and $F$. rubra. On the other hand, $F$. ovina showed the highest ion leakage under stress associated with the highest accumulation of $\mathrm{Na}^{+}$compared to other species. Nitrogen content differed significantly among species even under control. The highest nitrogen content was shown in $F$. arundinacea and the lowest in $F$. ovina. Similar results were shown in term of phosphorus content.

TABLE 1. Effect ( $F$ value) of salinity stress on shoot dry mass (DM), relative water content (RWC), ion leakage(IL), Proline, sodium (NA), potassium (K), calcium $(\mathrm{Ca})$, magnesium $(\mathrm{Mg})$, nitrogen $(\mathrm{N})$, and phosphorus $(\mathrm{P})$ in different Festuca grass species

\begin{tabular}{|c|c|c|c|c|c|c|c|c|c|c|}
\hline & \multicolumn{10}{|c|}{$F$ value } \\
\hline & DM & RWC & IL & Proline & Na & $\mathbf{K}$ & $\mathbf{C a}$ & Mg & $\mathbf{N}$ & $\mathbf{P}$ \\
\hline F. arundinacea & $7.97^{* * *}$ & $29.5^{* * * *}$ & 1.78 & 1.27 & $71.7^{* * * *}$ & 0.89 & 0.16 & 0.66 & $54.1^{* * * *}$ & $9.78^{* *}$ \\
\hline F. ovina & $13.3^{* * * *}$ & $7.07^{* * *}$ & $14.1^{* * * *}$ & $128.1^{\text {***** }}$ & $62.4^{* * * *}$ & 3.38 & 0.40 & $17.9^{* * * *}$ & $20.3^{* * * *}$ & $10.4^{* *}$ \\
\hline F.pratensis & $10.4^{* * *}$ & $7.45^{* *}$ & 3.28 & 2.08 & $181.4^{* * * * *}$ & 0.42 & 0.72 & 2.66 & $297.8^{* * * * *}$ & $6.96^{* *}$ \\
\hline F. rubra & $12.3^{* * * *}$ & $18.6^{* * * *}$ & $3.94^{*}$ & $103.1^{* * * *}$ & $697.8^{* * * * *}$ & $4.83^{*}$ & 0.88 & $5.14^{*}$ & $30.1^{* * *}$ & $13.3^{* * * *}$ \\
\hline
\end{tabular}

$,{ }^{* *},{ }^{* * *}$ Significant at probability of $0.05,0.01$ and 0.001 , respectively. 

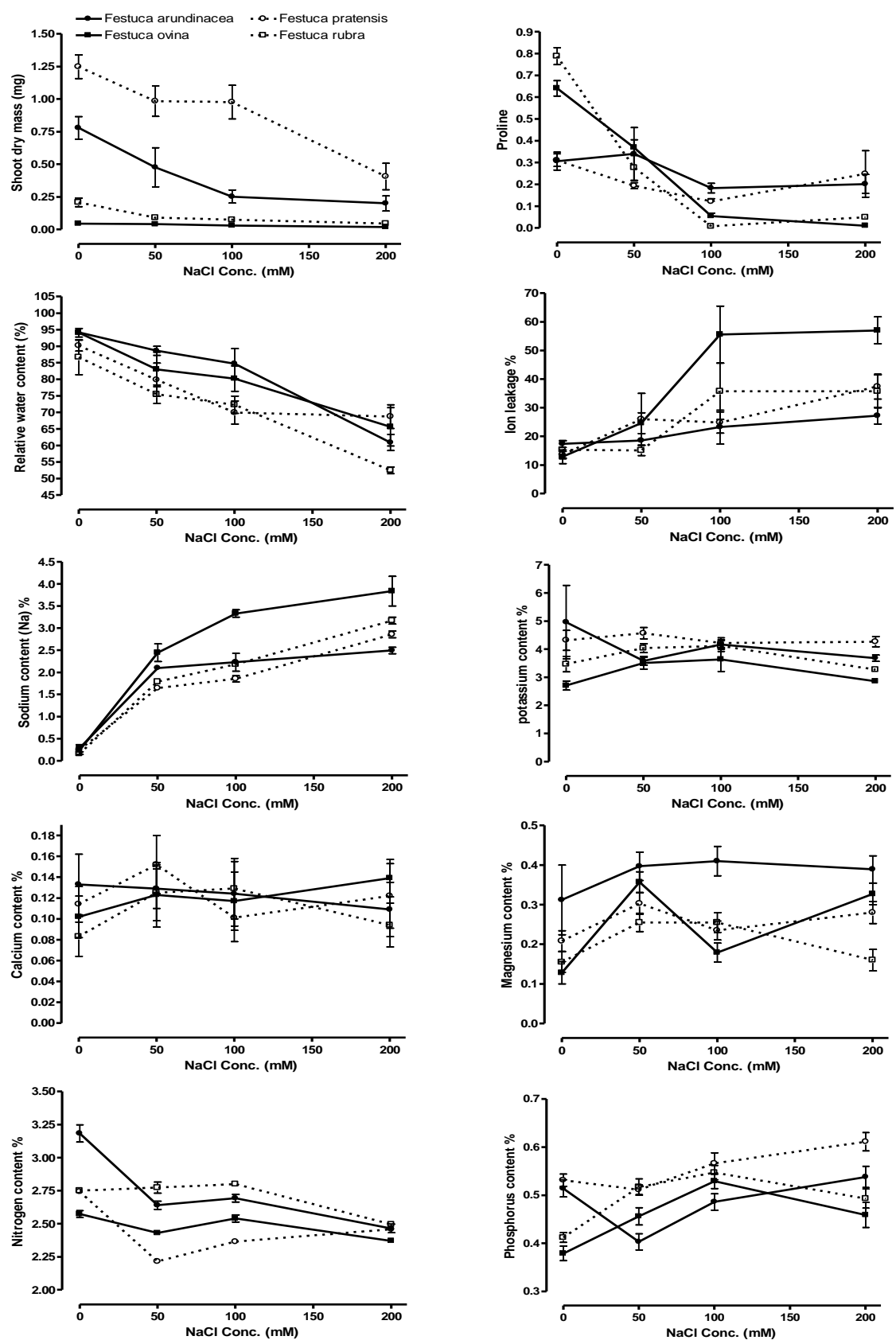

Fig.1. Responses of shoot dry mass, proline content, relative water content, ion leakage, and sodium, potassium, calcium, magnesium, nitrogen, and phosphorus contents in four Festuca grass species at different levels of salinity stress.

Egypt. J. Hort. Vol. 43, No.1 (2016) 


\section{Discussion}

In previous study under controlled conditions, Sugiyama (2005) revealed an interspecific difference in shoot relative growth rate (RGR) among grass species including Festuca species, which is closely associated with variation in specific leaf area (SLA). Sabreen and Sugiyama (2008) found trade-off between RGR and leaf structural properties under optimum conditions with resistance and tolerance to $\mathrm{Cd}$ stress. The slow-growing species included $F$. ovina and $F$. rubra with low RGR and SLA showed higher resistance to stress, while the fast-growing species include $F$. arundinacea and $F$. pratensis with high RGR and SLA showed lower resistance (Sugiyama, 2005). The crop yield is the indicator of plant tolerance to stress. It is difficult to evaluate the effect of salinity under field conditions because of the variability within fields and interactions with other environmental stresses. This study was conducted to evaluate the response of slow- and fastgrowing Festuca grass species to different levels of salinity stress. The species showed great differences in shoot dry mass even under controlled conditions as a result of the difference among species in growth habit. Shoot dry mass decreased significantly under salinity stress condition. Slopes of linear regression of shoot dry mass against $\mathrm{NaCl}$ treatments were calculated to evaluate the difference in resistance ability among species. $F$. ovina had the highest resistance ability (greatest slope: -0.0001 ), followed by $F$. rubra (slope: -0.0007$), F$. arundinacea (slope: -0.0028), and finally $F$. pratensis (least slope: -0.004). These results clearly demonstrated that slow-growing species had much higher resistance ability to salinity stress compared to fast-growing species. This result revealed the important role of growth habit and leaf properties in success of individual plants under stress conditions.

Plant resistance to environmental stress such as salinity represents the ability of plant to reduce the negative impact of stress, which is based on two components: avoidance and tolerance (Munns \& Tester 2008 and Carillo et al., 2011). Avoidance is the ability of plant to escape from the stress conditions, while tolerance is the ability of plant to withstand the imposed stress (Levitt, 1972 and Pierce et al., 2005). In this study, $\mathrm{Na}^{+}$accumulation in shoots showed great variation among species (Fig. 1). The slow-growing species showed higher $\mathrm{Na}^{+}$accumulation rather than fast-growing species under salinity stress. These results revealed that slow-grown species had lower ability to reduce $\mathrm{Na}^{+}$ accumulation in shoots, and also greater ability to withstand the accumulated $\mathrm{Na}^{+}$ ion. These suggested that resistance to ionic toxicity caused by salinity stress is associated mainly with the ability to tolerate the accumulated $\mathrm{Na}^{+}$ions rather than avoidance ability. This is consistent with resistance to cadmium (Cd) stress (Zha et al., 2004 and Sabreen \& Sugiyama, 2008).

Salinity had negative impact on physiological process such as water relations (Maeda and Nakazawa, 2008), nutritional imbalance (Yang et al., 2008) and membrane stability (Dogan et al., 2010). Sodium sequestration and $\mathrm{K}^{+}$retention are crucial factors in salinity tolerance (Adem et al., 2014). Plants acclimate to salt stress by preventing $\mathrm{K}^{+}$leakage and $\mathrm{Na}^{+}$accumulation suggesting that salt Egypt. J. Hort. Vol. 43, No.1 (2016) 
tolerance is associated mainly with ion-specific component rather than osmotic component of stress (Pandolfi et al., 2012). In this study, salinity stress had negative effects on water status (measured by relative water content, RWC) and membrane stability of species (measured by ion leakage, IL). F. pratensis showed the highest RWC, while $F$, rubra showed the lowest RWC under salinity stress (Fig.1). No clear role of RWC in differences between slow- and fastgrowing species was evident. The slow-growing species showed significant increases in IL, while the fast-growing species showed no significant changes under stress. F. ovina showed the greatest IL compared to other species, in addition to the greatest $\mathrm{Na}^{+}$accumulation. Magnesium $(\mathrm{Mg})$ content increased significantly under salinity stress for slow-growing species, but no significant changes in fast-growing species. Also, $F$. ovina showed the greatest increase in $\mathrm{Mg}$ content under stress compared to other species. These results indicate occurrence of membrane damage as a result of $\mathrm{Na}^{+}$ion toxicity, $\mathrm{Mg}$ may play importance role in tolerance mechanism.

Compatible osmolytes, such as proline, are low molecular weight, highly soluble organic compounds synthesis and accumulating in varied amounts depending on plant species. The major functions for these osmolytes are protecting the structure and maintaining osmotic balance within the cell through different course, including contribution to cellular osmotic adjustment, detoxification of reactive oxygen species, protection of membrane integrity, and stabilization of enzymes/proteins (Bohnert \& Jensen, 1996 and Hasegawa et al., 2000). Proline acts as a component of signal transduction pathways that regulate stress responsive genes by protecting the protein turnover machinery against stress-damage and up-regulating stress protective proteins (Khedr et al., 2003). Proline functions as an osmolyte for the intracellular osmotic adjustment and plays a critical role in protecting photosynthetic activity under salt stress (SilvaOrtega et al., 2008). Also, proline decreases the level of reactive oxygen species and lipid peroxidation as well as improves membrane integrity by increasing antioxidant gene providing a protection against $\mathrm{NaCl}$-induced cell death (Banu et al., 2009). The exogenous proline mitigated the detrimental effects of salt stress by increasing antioxidant enzyme activities (Hoque et al., 2007). In this study, the species showed great differences in proline content even under control conditions. Table 1 and Fig. 1 showed that slow-growing species, F. ovina and $F$. rubra, had higher proline content under control conditions compared to fastgrowing species, and the proline content decreased significantly under salinity stress. The fast-growing species showed no significant changes in proline content under salinity stress. These results suggest that slow-growing species had higher ability to use proline for reducing the negative impacts of salinity stress. The protective role of proline may be induced as a result of damage in membrane stability.

Salinity stress can have effects on plant growth and development in different ways including osmotic stress, ionic stress, and oxidative stress. Resistance of salinity stress is a complex trait. It is important to understand the tolerance mechanism to improve plant growth and productivity under stress. The results of 
these study suggested that the ionic stress is the main cause of damage rather than osmotic stress. The resistance to salinity stress is due to the ability of species to tolerate the ionic stress rather than the ability to avoid the accumulation of toxic ions. The great variation among species in their response to salinity stress is due mainly to the difference in growth properties. The results suggest also the important role of proline in salinity stress tolerance.

Acknowledgment: W.S. Soliman received financial support from the Egyptian government in the form of a postdoctoral scholarship.

\section{References}

Adem, G.D., Roy, S.J., Zhou, M., Bowman, J.P. and Shabala, S. (2014) Evaluating contribution of ionic, osmotic and oxidative stress components towards salinity tolerance in barley. BMC Plant Biol., 14, 113-115.

Amjad, A., Akhtar, J., Anwar-ul-Haq, M., Ahmad, R. and Zaid, M. (2014) Characterozation of comparative response of fifteen tomato (Lycopersicon esculentum Mill.) genotypes to $\mathrm{NaCl}$ stress. J. Agr. Sci. Tech., 16, 851-862.

Banu, N.A., Hoque, A., Watanabe-Sugimoto, M., Matsuoka, K., Nakamura, Y., Shimoishi, Y. and Murata, Y. (2009) Proline and glycline betaine induce antioxidant defense gene expression and suppress cell death in cultured tobacco cells under salt stress. J. Plant Physiol., 66, 146-156.

Bartels, D. and Sunkar, R. (2005) Drought and salt tolerance in plants. Critical Rev. Plant Sci., 24, 23-58.

Bates, L.S., Waldern, R.P. and Teare, I.D. (1973) Rapid determination of free proline for water-stress studies. Plant Soil, 39, 205-207.

Bohnert, H.J. and Jensen, R.G. (1996) Strategies for engineering water-stress tolerance in plants. Trends Biotechnol., 14, 89-97.

Carillo, P., Annunziata, M.G., Pontecorvo, G., Fuggi, A. and Woodrow, P. (2011) "Salinity Stress and Salt Tolerance. Abiotic Stress in Plants- Mechanisms and Adaptations". Shanker, A. (Ed.). http://www.intechopen.com/books/abiotic-stress-inplants-mechanissms-and-adaptations/salinity-stress-and-salt-tolerance.

Deinlein, U., Stephan, A. B., Horie, T., Luo, W., Xu, G. and Schroeder, J.I. (2014) Plant salt-tolerance mechanisms. Trends Plant Sci., 19, 371-379.

Dogan, M., Tipirdamaz, R. and Demir, Y. (2010) Salt resistance of tomato species grown in sand culture. Plant Soil Environ., 56, 499-507.

FAO (2011) Land and plant nutrition management service. http://www. fao. org/ ag/ agl/agll/spush

Flowers, T.J. and Hajibegheri, M.A. (2001) Salinity tolerance in Hordeum vulgare: ion concentration in root cells of cultivars differing in salt tolerance. Plant Soil, 231, 1-9.

Egypt. J. Hort. Vol. 43, No.1 (2016) 
Flowers, T.J. and Yeo, A.R. (1995) Breeding for salinity resistance in crop plants: where next?. Aust. J. Plant Physiol., 22, 875-884.

Hasegawa, P.M., Bressan, R.A., Zhu, J.K. and Bohnert, H.J. (2000) Plant cellular and molecular responses to high salinity. Annual Rev. Plant Biol., 51, 463-499.

Hoque, M.A., Okuma, E., Banu, M.N.A., Nakamura, Y., Shimoishi, Y. and Murata, Y. (2007) Exogenous proline mitigates the detrimental effects of salt stress more than exogenous betaine by increasing antioxidant enzyme activities. J. Plant Physiol., 164, $553-561$.

Jiang, Y. and Huang, B. (2002) Protein alterations in tall fescue in response to drought stress and abscisic acid. Crop Sci., 42, 202-207.

Khedr, A.A., Abbas, M.A., Abdel Wahid, A.A., Paul Quick, W. and Abogadallah, G.M. (2003) Proline induces the expression of salt-stress-responsive proteins and may improve the adaptation of Pancratium maritimum L. to salt-stress. J. Exp. Bot., 54, 2553-2562.

Levitt, J. (1972) “Responses of Plants to Environmental Stresses”. New York, NY, USA: Academic Press.

Loutfy, N., El-Tayeb, M.A., Hassanen, A.M., Moustafa, M.F.M., Sakuma, Y. and Inouhe, M. (2012) Changes in the water status and osmotic solute contents in response to drought and salicylic acid treatments in four different cultivars of wheat (Triticum aestivum). J. Plant Res., 125, 173-184.

Maeda, Y. and Nakazawa, R. (2008) Effects of the timing of calcium application on the alleviation of salt stress in the maize, tall fescue, and reed canary grass seedlings. Biol. Plant, 52, 153-156.

Mäser, P., Eckelman, B., Vaidyanathan, R., Horie, T., Fairbairn, D.J., Kubo, M., Yamagami, M., Yamaguchi, K., Nishimura, M., Uozumi, N., Robertson, W. Sussman, M.R. and Schroeder, J.I. (2002) Altered shoot/root $\mathrm{Na}^{+}$distribution and bifurcating salt sensitivity in Arabidopsis by genetic disruption of the $\mathrm{Na}^{+}$transporter AtHKT1. FEBS Lett., 531, 157-161.

Mitsuya, S., Kawasaki, M., Taniguchi, M. and Miyake, H. (2003) Relationship between salinity-induced damages and aging in rice tissues. Plant Prod. Sci., 6, $213-$ 218.

Munns, R. (2002) Comparative physiology of salt and water stress. Plant Cell Environ., 25, 239-250.

Munns, R. and Tester, M. (2008) Mechanisms of salinity tolerance. Annu. Rev. Plant Biol., 59, 651-681.

Pandolfi, C., Mancuso, S. and Shabala, S. (2012) Physiology of acclimation to salinity stress in pea (Pisum sativum). Environ. Exp. Bot., 84, 44-51. 
Pierce, S., Vianelli, A. and Cerabolini, B. (2005) From ancient genes to modern communities: the cellular stress response and the evolution of plant strategies. Func. Ecol., 19, 763-776.

Sabreen, S. and Sugiyama, S. (2008) Trade-off between cadmium tolerance and relative growth rate in 10 grass species. Environ. Exp. Bot., 63, 327-332.

Silva-Ortega, C.O., Ochoa-Alfaro, A.E., Reyes-Agüero, J.A., Aguado-Santacruz, G.A. and Jiménez-Bremont, J.F. (2008) Salt stress increases the expression of p5cs gene and induces proline accumulation in cactus pear. Plant Physiol. Biochem., 46 , 82-92.

Sugiyama, S. (2005) Relative contribution of meristem activities and specific leaf area to shoot relative growth rate in $\mathrm{C}_{3}$ grass species. Funct. Ecol., 19, 925-931.

Sugiyama, S. and Nikara, C. (2004) Differential contribution of avoidance and tolerance to dehydration resistance in populations of perennial ryegrass, Lolium perenne L. Aust. J. Agric. Res., 55, 33-37.

Taiz, L. and Zeiger, E. (2002) "Plant Physiology", $3^{\text {rd }}$ ed. Sunderland: Sinauer Associates.

Tester, M. and Davenport, R. (2003) $\mathrm{Na}^{+}$tolerance and $\mathrm{Na}^{+}$transport in higher plants. Ann. Bot., 91, 503-527.

Vinocur, B. and Altman, A. (2005) Recent advances in engineering plant tolerance to abiotic stress: achievements and limitations. Curr. Opin. Biotech., 16, 123-132.

Witzel, K., Weidner, A., Surabhi, G. K., Börner, A. and Mock, H. P. (2009) Salt stress-induced alterations in the root proteome of barley genotypes with contrasting response towards salinity. J. Exp. Bot., 60, 3545-3557.

Yang, C.W., Wang, P., Li, C.Y., Shi, D.C. and Wang, D.L. (2008) Comparison of effects of salt and alkali stresses on the growth and photosynthesis of wheat. Photosynthetica, 46, 107-114.

Zha, H.G., Jiang, R.F., Zhao, F.J., Vooijs, R., Schat, H., Barker, J.H.A. and McGrath, S.P. (2004) Co-segregation analysis of cadmium and zinc accumulation in Thlaspi caerilescens in interecotypic crosses. New Phytol., 163, 299-312. 


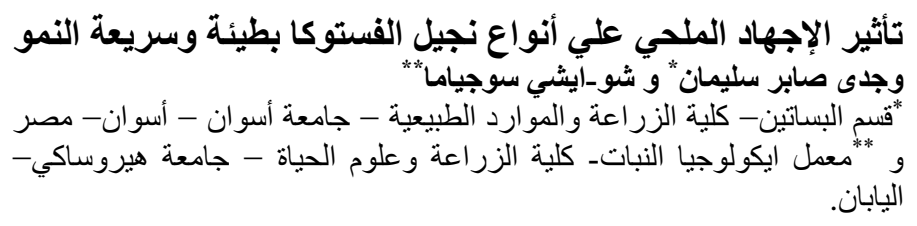

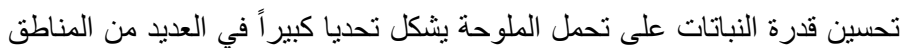

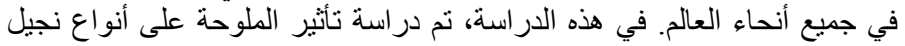

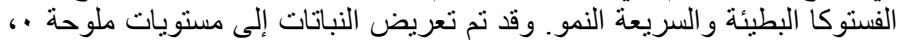

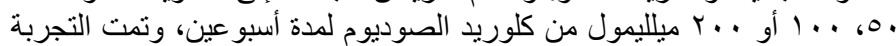

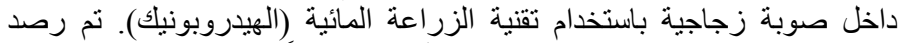

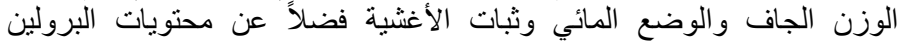

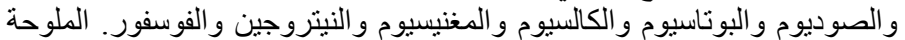

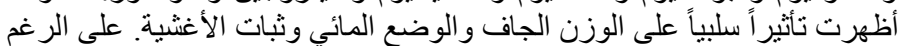

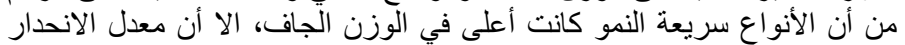

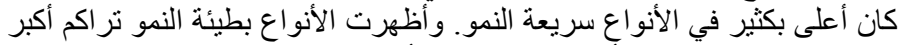

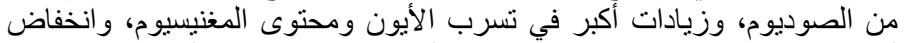

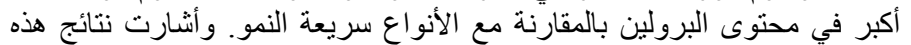

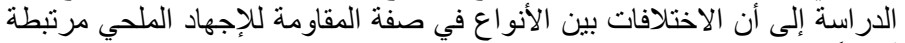

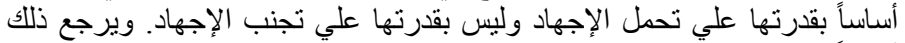

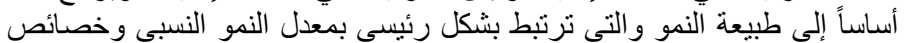

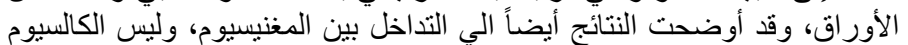

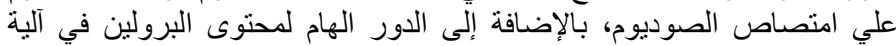

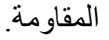

